\title{
Prediction of wave overtopping at vertical and nearly vertical structures
}

\author{
Amir Etemad-Shahidi* and Saeed Shaeri \\ Griffith School of Engineering, Gold Coast Campus, Griffith University, QLD 4222, Australia \\ a.etemadshahidi@griffith.edu.au
}

\begin{abstract}
Prediction of wave overtopping rate is an important step in the functional design of vertical coastal structures. In this study, scaling arguments and data mining approaches were used to derive formulae for the prediction of wave overtopping rate at vertical and nearly vertical structures. An extensive database mainly selected from the CLASH including impulsive and non-impulsive, low and high freeboard and composite structures were used for formula development. The obtained dimensionless overtopping rates were compared with those of existing formulae. The performances of formulae were assessed quantitatively using laboratory experiments, and it was shown that the developed formula is more accurate than the previous ones. In addition, the developed formula was validated using field measurements. Results indicated that the developed formula which considers the effects of all governing parameters performs better than the previous empirical formulae in predicting the overtopping rate in both laboratory and field experiments.
\end{abstract}

Keywords: wave overtopping rate; M5' model tree; vertical breakwaters; CLASH database; regression analysis

\section{INTRODUCTION}


Vertical and nearly vertical coastal structures such as seawalls are designed and constructed to protect coastal regions against storm waves and high water levels during storm surges. The overtopping rates must be lower than the allowable rate both in normal operating and extreme conditions to guarantee the safety of both people and assets on and behind the structures (Goda, 2009). Therefore, an accurate prediction of wave overtopping rate is very important in the design and safety assessment of structures. In addition, consequences of climate change such as sea level rise and its effects on wave climate make the existing coastal defense structure more vulnerable to overtopping (Chini and Stansby, 2012).

Different approaches such as empirical, process based and data mining approaches have been used for the prediction of overtopping rate in the last decade. Dimensional analysis and regression methods are commonly applied to data obtained from laboratory experiments to derive overtopping rate formulae. However, there is a large scatter (up to two orders of magnitude) between results obtained from different approaches and the measurements, especially for small overtopping rates (Andersen, 2006).

A major improvement in providing insight into the process of overtopping was the CLASH project (De Rouck et al., 2009). Analysis of dataset collected in this data set has resulted into different formulae such as those of EurOtop (Pullen et al., 2007), Goda (2009), and Van der Meer and Bruce (2014). However, there is still some level of divergence in the existing formulae (Van der Meer and Bruce, 2014). To resolve these issues, Van der Meer and Bruce (2014) reanalyzed the existing formulae and suggested a decision tree approach with six different power and exponential formulae for the prediction of wave overtopping rate. Recently Troch et al. (2014) studied the wave overtopping at low crest structures and noticed the low performance of existing formulae for steep slopes.

Due to the complexity of overtopping process, data mining approaches such as artificial neural network (ANN) have been used to predict mean wave overtopping rate for a wide range of coastal structures as a part of CLASH project. In EurOtop, an ANN model (Van Gent et al., 2007) was proposed for different 
types of coastal structures. In order to improve the prediction accuracy, Verhaeghe et al. (2008) developed a 2-phases neural prediction model to classify and quantify the overtopping rate. However, by contrast to empirical approaches, ANN models lacks transparency and do not provide physical insight (Jafari and Etemad-Shahidi, 2012).

The purpose of this study was to overcome the shortcomings of the previous approaches by providing physically sound and accurate formulae for estimation of wave overtopping rate at vertical and nearly vertical structures. To achieve this, scaling arguments and both traditional and Model Tree approaches were used to find an explicit relationship between dimensionless governing parameters. Model trees have been used widely in civil engineering problems (e.g. Bhattacharya et al. 2007; Sakhare and Deo, 2009; Bonakdar and Etemad-Shahidi, 2011; Etemad-Shahidi and Bali, 2011) recently. An extensive database including small and large scale experiments from CLASH Database (Van der Meer et al. 2009) and some other experiments were used to develop the formulae and the results were compared with those of the existing ones such as those given in EurOtop (Pullen et al., 2007), Goda (2009) and Van der Meer and Bruce (2014).

\section{Database}

The laboratory data set used in this study is a combination of the database created by the EU-financed CLASH project (De Rouck et al. 2009), and Allsop et al. (1995). In addition, full scale measurements of Samphire Hoe sea wall (Pullen and Allsop, 2003) were used for the validation. Within the CLASH project, an extensive database on wave overtopping, consisting of both small and large scale experiments, was created. The database includes many tests from different experiments conducted worldwide using different measurement tools and precisions. Details of the CLASH database and experiments can be found in Verhaeghe (2005) and Van der Meer et al. (2009). Experiments of Allsop et 
al. (1995) also consist of both small scale and large scale tests, conducted on vertical walls with a fixed (1:50) foreshore slope.

In total, the used data set contains 699 data points from 25 laboratory tests. The used field data from Samphire Hoe seawall were 23 full scale measurements at different water levels and storm conditions.

In the CLASH database a complexity factor $C F$, ranging from $C F=1$ for a very simple structure to $C F=4$ for complex composition of structures has been given to each structure. Similarly a reliability factor $R F$ ranging from $R F=1$ for a very reliable test to $R F=4$ for a non-reliable test (Van Gent et al. 2007) has been assigned to each test. In order to increase the reliability of the results, only data points with the data with $C F<4$ and $R F<4$ were used in this study. Furthermore, tests of the inclined structures or incidents waves with an angle of $>5^{\circ}$ were excluded. Noting that tests with very low overtopping rates may not be accurate due to measurement errors (Etemad-Shahidi and Jafari, 2014), tests with discharge rates $<1 \times 10^{-6} \mathrm{~m}^{3} / \mathrm{s} / \mathrm{m}$ were not used in further processing.

Scale and model effects are of concern in laboratory experiments. Therefore, field measurements were not used during the model development process to evade model confusion (Verhaege 2005, Jafari and Etemad-Shahidi, 2012). In other words, the model was developed based on the laboratory experiments and then validated using field measurements. The ranges of the dimensional parameters used in the current study are shown in table 1 . As seen the used data base has wide ranges of dimensional and dimensionless parameters.

\section{Evaluation of Existing formulas}

CLASH project was conducted to provide a comprehensive data set of overtopping rate and unify the different European design manuals. One of the outputs of this study was the publication of EurOtop (Pullen et al. 2007) and providing formulas for different structures. EurOtop recommends different 
formulae with different forms for breaking (impulsive) and nonbreaking (non-impulsive) waves. The probabilistic formula given for non-impulsive waves $(h *>0.3)$ is as follows:

$$
q^{*}=\frac{q}{\sqrt{g \cdot H_{m 0}^{3}}}=0.04 \exp \left(-2.6 \frac{R_{C}}{H_{m 0}}\right) \quad \text { for } 0.1<R_{c} / H_{m 0}<3.5
$$

Where $h *$ is the discriminating impulsiveness parameter defined as:

$$
h_{*}=1.35 \frac{h_{s}}{H_{m 0}} \frac{2 \pi h_{s}}{g T^{2}{ }_{m-1,0}}=1.35 \frac{h_{s}^{2}}{H_{m 0} L_{m-1,0}}
$$

$h_{s}$ is the water depth at the toe of the structure, $H_{m 0}$ is the wave height at the toe of the structure, $q$ is the mean overtopping discharge, $T_{m-1,0}$ is the mean wave period, $L_{m-1,0}$ is the deep water wave length, $q^{*}$ is the dimensionless overtopping rate, and $R_{C}$ is the crest freeboard. For cases with zero freeboard an average value of 0.062 is suggested for $q^{*}$.

For impulsive condition with $h *<0.2$, EurOtop suggests the following formulae

$$
\begin{aligned}
& q^{*}=\frac{q}{h_{*}^{2} \sqrt{g \cdot H_{m 0}^{3}}}=1.5 \times 10^{-4}\left(h_{*} \frac{R_{C}}{H_{m o}}\right)^{-3.1} \text { for } 0.03<h * R_{c} / H_{m 0}<1.0 \\
& q^{*}=\frac{q}{h_{*}^{2} \sqrt{g \cdot H_{m 0}^{3}}}=2.7 \times 10^{-4}\left(h_{*} \frac{R_{C}}{H_{m 0}}\right)^{-2.7} \text { for } h * R_{c} / H_{m 0}<0.02
\end{aligned}
$$

For other conditions, it is recommended to use the equation that gives the more conservative rate. In addition, a correction factor of 1.3 is given for 10:1 battered walls.

For composite walls with a berm or toe, $h *$ in eq. (1) needs to be replaced by a modified impulsiveness parameter defined as:

$$
d_{*}=1.35 \frac{d}{H_{m 0}} \frac{2 \pi h_{s}}{g T^{2}{ }_{m-1,0}}
$$

Where $d$ is the berm depth. For impulsive conditions, the following formula is recommended for composite walls: 
$q^{*}=\frac{q}{d_{*}^{2} \sqrt{g \cdot H_{m 0}^{3}}}=7.8 \times 10^{-4}\left(d_{*} \frac{R_{C}}{H_{m 0}}\right)^{-2.9}$ for $0.05<d * R_{c} / H_{m 0}<1.0$

Scatter diagram of the measured and predicted overtopping rates by the formulae given by EurOtop (Pullen et al. 2007) for the laboratory datasets is shown in Fig. 1. The inclined upper dashed line, solid line and lower dashed line are 10 times over estimated, perfect agreement, and 10 times under estimated lines, respectively. It is clear from Fig. 1 that there is a large scattering and predictions are mostly overestimated for low values of dimensionless discharge rates. This was also noticed by Goda (2009), especially in steep bed slopes in relatively shallow waters.

In an attempt to provide an improved and unified formula for wave overtopping rate at vertical and inclined walls, Goda (2009) reanalyzed the CLASH laboratory datasets. He noticed the inadequacy of EurOtop formulae for shallow water with steep slope condition. Using the exponential function form, Goda (2009) included the effects of seabed slope and relative toe depth derived the following formula for wave overtopping rate:

$\frac{q}{\sqrt{g H^{3}{ }_{m 0}}}=\exp \left(-A-B \frac{R_{C}}{H_{m 0}}\right)$

Where $A$ and $B$ are functions of sea bed slope $(\tan \theta)$, structure slope ( $\cot \alpha)$ and relative toe depth as

$$
\left\{\begin{array}{l}
A=A_{0} \tanh \left[(0.956+4.44 \tan \theta) \times\left(\frac{h_{s}}{H_{m 0}}+1.242-2.032 \tan ^{0.25} \theta\right)\right] \\
B=B_{0} \tanh \left[(0.822-2.22 \tan \theta) \times\left(\frac{h_{s}}{H_{m 0}}+0.578+2.22 \tan \theta\right)\right]
\end{array}\right.
$$

where

$$
\left\{\begin{array}{l}
A_{0}=3.4-0.734 \cot \alpha+0.239 \cot ^{2} \alpha-0.0162 \cot ^{3} \alpha \\
B_{0}=2.3-0.5 \cot \alpha+0.15 \cot ^{2} \alpha-0.011 \cot ^{3} \alpha
\end{array}: 0 \leq \cot \alpha \leq 7\right.
$$


The main advantage of this approach is its simplicity, even though the physical justification of $A$ and $B$ values is difficult. Scatter diagram of the measured and predicted overtopping rates by the formula of Goda (2009) is shown in Fig. 2. As seen, the data points are scattered more or less symmetric around the line of perfect agreement, implying that the Bias of this approach is less than that of EurOtop. However, the uncertainty of the predictions for low discharge rates is still high.

Recently, Van der Meer and Bruce (2014) also revisited the CLASH data set to reunify its formulae for sloping and vertical structures. They noticed that the overtopping rate depends on the relative berm depth $\left(d / h_{s}\right)$, bed slope, wave impulsiveness and relative freeboard. They suggested a decision chart (Fig. 3) with six different formulae for the prediction of wave overtopping rate at vertical or composite walls to improve the accuracy of the predictions (hereafter called VB). Fig. 4 shows the comparison between the measured overtopping rates and the predicted ones by the formulae of Van der Meer and Bruce (2014). As seen, there is still some disagreement between the predicted and measured values, especially at low discharge rates. Fig. 4 also demonstrates the Van der Meer and Bruce (2014) formulae generally overestimate the discharge rates and therefore are conservative.

\section{Model Tree}

Machine learning M5 model tree (Quinlan, 1992) is a popular approach which uses information theory to split the data progressively. The splitting criterion in this algorithm is based on treating the standard deviation of the output values, and calculating the expected reduction in the error (Wang and Witten, 1997).

Model trees which utilize a divide-and-conquer principle are a machine learning technique for dealing with continuous class learning problems (Quinlan, 1992). The fundamental concept behind constructing a model tree is simple. In the first stage, all enumerated variables are transformed into binary variables 
and the values in the enumeration are sorted by average class values. This model has been embodied in a learning algorithm called M5. Model trees combine a conventional decision tree with possible linear regression functions at the leaves. The standard deviation reduction of the class values that reach a node is used for the splitting criterion. After examining all possible splits, M5 algorithm selects the one that maximizes the expected error reduction. Then, in pruning stage, the resulted linear model is simplified by dropping some terms to minimize the estimated error using the multiplication factor $n+v / n-v$, where $n$ is the number of training examples that reaches the node and $v$ is the number of parameters in the model that represents the class value at that node (Quinlan, 1992). The terms are dropped one by one, as long as the estimated error decreases. Once a linear model is developed for each interior node, the tree is pruned back from the leaves as long as the expected estimated error decreases. Finally, for increasing the accuracy of prediction, smoothing process will be carried out to compensate for the sharp discontinuities that will occur between adjacent linear models at the leaves of the pruned tree. M5' algorithm is an implementation of M5 technique introduced by Quinlan (1992) for inducing trees of regression models to deal with continuous class learning problems with enumerated attributes (Wang and Witten, 1997) Thus all splits in M5' involve either a continuous valued attribute or a synthetic binary one. The solution in M5' is to multiply the standard deviation reduction $(S D R)$ value by a correction factor $\beta$ that is unity for a binary split and decays exponentially as the number of values increase:

$$
S D R=\frac{M}{|T|} \times \beta(i) \times\left[s d(T)-\sum \frac{\left|T_{i}\right|}{|T|} \times s d\left(T_{j}\right)\right]
$$

Where $M$ is the number of examples without missing values for that variable, $T$ is the set of examples that reaches the node and, $T_{i}$ is the set that results from splitting the node according to the chosen attributes (Wang and Witten, 1997). Techniques devised by Breiman et al. (1984) are adopted in M5' algorithm to deal effectively with enumerated variable. 


\section{Results and Discussion}

Wave overtopping occurs in two forms: most of the wave overtopping discharges are observed when the wave run-up is higher than the crest level, while the remaining part of wave overtopping are due to wave-breaking fine droplets carried over by the crest of the structure by their momentum or wind (Verhaeghe 2005). The following dimensional parameters were considered as the governing ones on the overtopping rate at vertical or near vertical walls:

$q=f\left(R_{C}, H_{m 0}, d, h_{s}, L_{m-1,0}, \cot \alpha, \tan \theta\right)$

These parameters and their ranges are shown in table 1. Noting the limited range of cot $\alpha$ in the used data set, this parameter was not used in further processing. This could be justified by noting that effect of a sloping structure fades out when $\cot \alpha<0.2$ (Troch et al., 2014).

For the development of formulae, dimensionless parameters were selected to include all the possible governing parameters. Table 2 displays parameters used in developing the new formulae. As seen, they cover a wide range and in addition to the commonly used ones, other dimensionless parameters, such as wave steepness, relative water depth and relative berm depth were considered. After choosing these input and output parameters, M5' was applied for the prediction of overtopping discharge rate. To develop the formulae, about two third of laboratory data points were randomly selected and used as the training data set. The remaining data points were used for the testing the formulae. As M5' model tree can only produce linear relationship between input and output parameters, the model was developed using log of input and output parameters. Several formulae, using various dimensionless parameters and their combinations, were developed. Finally, the one which outperformed the other ones (MT1) was selected as follows.

$R_{c} / H_{m 0} \leq 1.19$ 


$$
q^{*}=37.1 \times 10^{-3} \tan \theta^{0.020} \exp \left(-0.148 d^{*}\right) \exp \left(0.198 H m_{0} / h_{s}\right) \exp \left(-2.414 R_{c} / H_{m 0}\right)
$$

$R_{c} / H_{m 0}>1.19$ and $H_{m 0} / h_{s}>0.52:$

$$
q^{*}=4.8 \times 10^{-3} \tan \theta^{0.326} \exp \left(0.234 H_{m 0} / h_{s}\right) \exp \left(-1.005 R_{c} / H_{m 0}\right)
$$

$R_{c} / H_{m 0}>1.19$ and $H_{m 0} / h_{s} \leq 0.52$ :

$$
q^{*}=4.5 \times 10^{-3} \tan \theta^{0.046} \exp \left(0.351 H_{m 0} / h_{s}\right) \exp \left(-0.967 R_{c} / H_{m 0}\right)
$$

The used algorithm selected $R_{c} / H_{m}$ and $H_{m 0} / h_{s}$ as the discriminator parameters. The discriminator parameters and their value do not necessarily have any physical interpretation since they are found by minimizing the error (Bhattacharya et al., 2007). However, the selection of these parameters is physically sound because if the crest of the structure is low, both the rising water and fine droplets can pass over it; and $H_{m 0} / h_{s}$ is an indicator of wave breaking. The critical value of about 1.2 for $R_{c} / H_{m 0}$ is within the proposed values of 0.8-1.35 suggested by Van Der Meer and Bruce (2014) and Victor and Troch (2012). The obtained formulae also show that for low crested structures $\left(R_{c} / H_{m 0} \leq 1.2\right)$, overtopping rate is indirectly related to the relative freeboard and directly to the wave height to water depth ratio; while the bed slope has a direct but minor influence on the overtopping rate. These are in line with the findings of Goda (2009) where he used hyperbolic tangent functions to include the effects of water depth and bed slope (see also Van der Meer and Bruce, 2014).

For high crested Structures $\left(R_{c} / H_{m 0}>1.2\right)$, two formulae are given for breaking/impulsive condition $\left(H_{m 0} / h_{s}>0.52\right)$ and nonbreaking/nonimpulsive condition $\left(H_{m 0} / h_{s}<0.52\right)$. Again the obtained discriminator value is in agreement with the existing knowledge about wave breaking and depth limited waves (e.g. Van der Meer and Bruce, 2014). When $H_{m 0} / h_{s}$ is greater than about 0.6 , the wave has less chance to break and produce droplets; and overtopping is limited. The formulae for high crested structures correctly show that by an increase of the relative crest freeboard, it becomes less important (smaller coefficients) while the roles of water depth and bed slope become more pronounced. 
Scatter diagrams of the measured and predicted dimensionless overtopping discharges for test and train data points are shown in Fig. 5. As seen, compared to the previous empirical formulae (Figs. 1,2 and 4), the predicted values are more concentrated around the optimal line. In addition, there is a few cases of large underestimation $\left(q^{*}{ }_{\text {pred }}<0.10 q^{*}\right.$ meas $)$ and only one case of large overestimation $\left(q^{*}{ }_{\text {pred }}>10 q^{*}\right.$ meas $)$. As discussed before, model tree divides the input parameter space into a number of sub-spaces and in each sub-space it builds a local formula. One of the shortcomings of the developed formulae is the potential discontinuity between two local neighboring formulae, even though the M5' algorithm uses smoothing process to reduce the discontinuities to some extent. This is mainly because no single method can give a perfect discriminator (Pullen et al., 2007).

Different approaches such as using a separator model and/or using multivariate nonlinear regression have been used to overcome this issue (e.g. Etemad-Shahidi et al., 2011; Jafari and Etemad-Shahidi, 2012). Here, we also investigated other (non-conventional) forms for predicting the discharge rate to circumvent this issue and develop a simpler formula. As discussed by Goda (2009), a unified formula is easier to use and there is no need to classify the possible conditions noting that the overtopping rate is due to the combination of non-breaking, breaking and broken waves within a single train of random waves.

Different functional form of formulae with different levels of complexity and accuracy were trained and tested. Finally, a simple form with a high level of accuracy (MT2) was found as follows:

$q^{*}=1.505 \tan \theta^{0.213}\left(d / H_{m 0}\right)^{0.457} \exp \left[-6.02\left(R_{c} / H_{m 0}\right)^{0.403}\left(h_{s} / H_{m 0}\right)^{0.123}\left(H_{m 0} / L\right)^{0.044}\right]$

The main advantages of this formula are its simplicity and clarity. As seen, in contrast to most of the previous formulae, an explicit and unified formula is given for all possible cases (e.g. high/low crested, impulsive/non impulsive conditions). 
The functional form of the developed formula is somehow similar to the recent formulas suggested for overtopping discharge at inclined smooth structures (Van der Meer and Bruce, 2014; Etemad-Shahidi and Jafari, 2014). Moreover, in eq. 12, the effects of all governing parameters including bed (foreshore) slope $(\tan \theta)$, relative berm depth $\left(d / H_{m 0}\right)$, relative crest freeboard $\left(R_{c} / H_{m 0}\right)$, relative water depth $\left(h_{s} / H_{m 0}\right)$ and wave steepness $\left(H_{m 0} / L_{m-1,0}\right)$ are shown explicitly. As seen, the overtopping rate strongly depends on relative crest freeboard and then relative water depth while the bed slope has a direct but marginal effect on it. The correlation between overtopping rate and bed slope is consistent with the findings of Goda (2009) and Van der Meer and Bruce (2014) where they noted that a sloping foreshore results in larger overtopping rates.

By increasing the relative crest freeboard, relative water depth, and to some extent wave steepness, the overtopping rate decreases; in accordance with the recent findings of Van der Meer and Bruce (2014). On the other hand, existence of a berm or steeper foreshore results in larger overtopping rate, a fact previously shown implicitly in Goda (2009) formula. Interestingly in this formula, the power of $d$ is nearly the same as the one used in the decision chart suggested by Van der Meer and Bruce (2014), formulae suggested by Allsop et al. (1995) and Pullen et al. (2007).

In terms of dimensional parameters, eq. 12 indicates that the discharge rate is indirectly correlated to the crest freeboard and water depth; and directly correlated to wave height and wave length (period), similar to the recent findings about wave overtopping at smooth and impermeable structures (e.g. Van der Meer and Bruce, 2014; Etemad-Shahidi and Jafari, 2014).

Fig. 6 shows the (dimensionless) overtopping rates predicted by eq. 12 versus the measured values. This figure clearly shows that, compared to the previous empirical formulae and MT1 (Figs. 1, 2, 4 and 5), the predictions are more concentrated around the optimal line. Besides, there are few large 
underestimation cases $\left(q^{*}\right.$ pred $<0.10 q^{*}$ meas $)$ which is very important for a safe design and limited number of large overestimation $\left(q^{*}{ }_{\text {pred }}>10 q^{*}{ }_{\text {meas }}\right)$ which is important for an economic design.

To have a quantitative comparison of the formulae, accuracy metrics such as $B I A S$, root mean square error $(R M S E)$, Index of agreement $\left(I_{a}\right)$ and discrepancy ratio $(D R)$ were used (Etemad-Shahidi and Taghipour, 2012). These measures are defined as:

$$
\begin{aligned}
& B I A S=\frac{1}{n} \sum_{i=1}^{n}\left(\log q_{\text {pred }_{i}}^{*}-\log q_{\text {meas }_{i}}^{*}\right) \\
& R M S E=\sqrt{\frac{1}{n} \sum_{i=1}^{n}\left(\log q_{\text {pred }_{i}}^{*}-\log q_{\text {meas }_{i}}^{*}\right)^{2}} \\
& I_{a}=1-\frac{\sum_{i=1}^{n}\left(\log q_{\text {pred }_{i}}^{*}-\log q_{\text {meas }_{i}}^{*}\right)^{2}}{\sum_{i=1}^{n}\left(\left|\log q_{\text {pred }_{i}}^{*}-\bar{X}\right|+\left|\log q_{\text {meas }_{i}}^{*}-\bar{Y}\right|\right)^{2}} \\
& D R_{i}=\log \left(\frac{q_{\text {pred }_{i}}^{*}}{q_{\text {meas }_{i}}^{*}}\right)
\end{aligned}
$$

Where $q^{*}$ meas and $q^{*}$ pred are the dimensionless measured and predicted overtopping rate values, $n$ is the number of data, and $\bar{X}$ and $\bar{Y}$ are respectively the average of $\log q^{*_{\text {pred }}}$ and $\log q^{*}{ }_{\text {meas }}$.

Table 3 displays the accuracy metrics of both developed and existing formulae for laboratory experiments. The values of these accuracy metrics show the large uncertainties of empirical equations for prediction of overtopping rate. As seen, most of the accuracy metrics of MT1 show improvement in the prediction of overtopping rates. This table also shows that within the previous formulae, EurOtop outperforms others in laboratory experiments with smaller BIAS and RMSE. The overtopping rates obtained from MT1 and eq. 12 are nearly unbiased as well while the RMSE of eq. 12 is lower than others. In other words, they yield more accurate predictions. 
The BIAS values of the new formulae show a negligible overestimation, while both EurOtop and VB models generally overestimate the overtopping rate. $R M S E$ is generally interpreted as another performance indicator gaging the scatter of predictions. As shown in the Table 3, the predictions of the new formulae are also less scattered than those of previous ones. The correlation coefficient makes sense together with BIAS. As seen in the Table 3, eq. 12 has the largest $I_{a}$ value in both data bases and performs better than previous empirical formulae. It is noteworthy that by contrast to other approaches, that have up to 6 formulae, MT2 consists of only one formula.

The closeness of predictions with measurement was also judged qualitatively by plotting the histogram of $D R$ values (Fig. 7). A $D R$ value of zero means an exact matching between measured and predicted overtopping rates. It is clear from this figure that $D R$ values for most of the MT1 and eq. 12 predictions are close to zero and their distributions are nearly symmetrical. However, Van der Meer and Bruce (2014) and Pullen et al. (2007) formulae have a positive skewness. Only 37\% of VB predictions are more than 2 times larger or smaller than the measured overtopping rates. This high performance is followed by that of eq. 12 where about $41 \%$ of its predictions are more than 2 times smaller or larger than the measured overtopping rates. The last two rows of Table 3 are also related to the discrepancy ratio $(D R)$ statistics. The calculate $D R$ ranges show that narrowest ones belong to MT1 and eq. 12; and then that of EurOtop. This table also shows that about $95 \%$ of MT1 predictions are within $-1<D R<1$ range while that of Goda (2009) is about $91 \%$.

A good formula is a formula that its errors are independent of the input parameters (Sahay and Dutta 2009). Fig. 8 shows the $D R$ values of different formulae as a function of $R_{C} / H_{m o}$. As seen the discrepancy ratio of Goda (2009) formula is sensitive and indirectly correlated the relative crest freeboard while this behavior is not seen in eq. 12 and other formulae. 


\section{Application to full scale measurements}

A major concern regarding the applicability of overtopping formulae derived from laboratory experiments is scale and model effects. In order to investigate these effects, the formulae were applied to the field measurements of Samphire Hoe (Pullen and Allsop, 2004) during two storms. It should be mentioned that Samphire Hoe seawall is not exactly vertical and has three stepping back sections. The measured values were compared with those predicted by the developed formulae, EurOtop (Pullen et al., 2007), Goda (2009), and the set of formulae proposed by Van der Meer and Bruce (2014).

Application of the formulae to the field measurement has yielded the scatter plot shown in Fig. 9. As seen, generally, all the formulae over predict the measured values while the predictions of eq. 12 and then EurOtop are more accurate than those of others. This is better seen in Table 4 where the accuracy metrics are given. As seen, eq. 12 has the lowest $B I A S$ and $R M S E$ values, highest $I_{a}$, narrowest range of $D R$; and nearly $90 \%$ of the eq. 12 predictions lie in the range of $0.10 q^{*}$ meas $<q^{*}{ }_{\text {pred }}<10 q^{*}$ meas.

Table 4 also indicates that all the formulae have performed worse in this case and particularly their BIAS values have increased. This can be justified by noting that during the first storm (nearly half of the data points), blowing wind reduced the discharge rates measured by tanks (Pullen and Allsop, 2004) which leads to the overestimation of overtopping rates obtained from laboratory experiments (without wind). As seen from accuracy metrics; eq. 12 still performs well and is followed by EurOtop.

As discussed by Guven and Gunal (2008), the significant shortcoming of conventional formulae is that they are restrained by the used functional form which may not completely conform to the physics of the observations. The predicted wave overtopping rates predicted by empirical formulae have a wide range of uncertainty (even using laboratory measurements). This is mainly because of uncertainties originated from the complex nature of wave overtopping process associated with random waves. In order to consider the uncertainty in the predictor models, commonly standards and guidelines recommend a 
safety margin of about one standard deviation. Assuming a normal probability distribution (Victor and Troch, 2012), the following formula is suggested for deterministic design or safety assessment of vertical structures:

$q^{*_{0}}=10^{0.5 N} \times 1.505 \tan \theta^{0.213}\left(d / H_{m 0}\right)^{0.457} \exp \left[-6.02\left(R_{c} / H_{m 0}\right)^{0.403}\left(H_{m 0} / h_{s}\right)^{-0.123}\left(H_{m 0} / L\right)^{0.044}\right]$

where $N$ depends on the acceptable level of exceedance or risk given in Table 5. For example, if the acceptable level of risk is $10 \%$, then $N$ should be selected as 1.28 and enhancement factor would be 4.37 .

To sum up, in the development of formulae, minimum effort was spent compared to those required by other commonly used data mining approaches. For example, Artificial Neural Networks and Adaptive Neuro Fuzzy Inference System need some trial and error for finding optimum parameters (e.g. Kazeminezhad et al. 2010). Although they are able to produce accurate results (e.g. Verhaeghe et al. 2008; Etemad-Shahidi and Mahjoobi, 2009), they are unable to provide explicit mathematical expressions. However, the used approach has the ability to provide an explicit and simple formula that can be easily used by coastal engineers for design of vertical breakwaters.

As discussed by Etemad-Shahidi and Bonakdar (2009), the main restriction in using M5' is that it only can provide linear relationships between input and output parameters. Therefore, proper parameter transformations may be required to develop an optimum model. In other words, use of an appropriate functional form and appropriate preprocessing of parameters is required for developing a robust model, i.e. a simple and accurate one. It should be noted that eq. 17 is valid in the range of data used in this study.

\section{SUMMARY AND CONCLUSIONS}

In this study, dimensional analysis and data mining approaches were used to develop compact and physically justifiable formulae for overtopping rate at vertical and nearly vertical structures. The existing 
laboratory tests, extracted mainly from the CLASH database, were used to develop the formulae using all the governing parameters. To do so, the data points were separated to test and train subsets. First, traditional functional forms were assumed and using M5', three exponential formulae were obtained for different relative freeboard and wave height regimes. Then, other forms of functional relationship rate were investigated and a single non-conventional formula which directly includes the effects of all governing parameters was obtained. The proposed formulae were validated using the laboratory test datasets and their performances were compared with those of previous ones using accuracy metrics. Results showed that the derived formulae outperform the previous formulae both in terms of accuracy and simplicity. In order to investigate the scale / model effects and robustness of the derived formulae, the performances of all approaches were assessed using limited existing field measurements and it was found that the new formulae are applicable to both laboratory and field data. Finally, to provide a tool for deterministic design and safety assessment, the formula was modified to consider the risk level.

\section{ACKNOWLEDGEMENTS}

The authors would like to acknowledge the organizers of EC-project CLASH for their comprehensive and freely available database on the wave overtopping phenomenon. The University of Waikato is highly appreciated for proving the WEKA software. We are also grateful to Prof Van der Meer for the used dataset and Dr. M.H. Kazeminezhad and Ebrahim Jafari for their fruitful comments. 


\section{REFRENCES}

Allsop, N. W. H., Besley, P., and Madurini, L., 1995. Overtopping performance of vertical walls and composite breakwaters, seawalls andlow reflection alternatives. Final Rep. of Monolithic Coastal StructuresProject, Univ. of Hannover, Hannover, Germany.

Bhattacharya, B.,Price, R. K. and Solomatine, D. P., 2007. Machine learning approach to modeling sediment transport. Journal of Hydraulic Engineering-ASCE, 133, 440-450.

Bonakdar, L. and Etemad-Shahidi, A., 2011. Predicting wave run-up on rubble-mound structures using M5 model tree, Ocean engineering, 38,111-118

Breiman, L., Friedman, J.H., Olshen, R. A. and Stone, C. J. , 1984. Classification and Regression Trees, Wadsworth \& Brooks/Cole Advanced Books \& Software, Pacific Grove, CA

Chini N and Stansby, P. , 2012. Extreme values of coastal wave overtopping accounting for climate change and sea level rise, Coastal Engineering, 65, 27-37

De Rouck, J.,Verhaeghe, H. and Geeraerts, J. , 2009. Crest level assessment of coastal structures General overview. Coastal Engineering, 56, 99-107.

Etemad-Shahidi, A. and Bonakdar, L., 2009. Design of rubble mound breakwaters using M5' machine learning method. Applied Ocean Research, 31, 197-201.

Etemad-Shahidi, A. and Mahjoobi, J., 2009. Comparison between M5' model tree and neural networks for prediction of significant wave height in Lake Superior. Ocean Engineering, 36, 1175-1181.

Etemad-Shahidi, A. and Bali, B., 2011. Stability of rubble-mound breakwater using H50 wave height parameter, Coastal Engineering, 59, 38-45.

Etemad-Shahidi, A., Yasa, R and Kazeminezhad, M.K., 2011. Prediction of wave-induced scour depth under submarine pipelines using machine learning approach, Applied Ocean Research, 33, 54-59. 
Etemad-Shahidi, A. and Jafari, E. , 2014. New formulas for prediction of wave overtopping at inclined structures with smooth impermeable surface, Ocean Engineering, 84, 124-132.

Etemad-Shahidi, A., and Taghipour M., 2012. Predicting Longitudinal Dispersion Coefficient in Natural Streams Using M5' Model Tree, ASCE J. Hydraulic Engineering, 138, 542-554.

Goda, Y., 2009. Derivation of unified wave overtopping formulas for seawalls with smooth, impermeable surfaces based on selected CLASH datasets. Coastal Engineering, 56, 385-399.

Guven A and Gunal M., 2008. Genetic programming approach for prediction of local scour downstream of hydraulic structures, ASCE Journal of Irrigation and Drainage Engineering, 134, 241-249.

Jafari, E. and Etemad-Shahidi, A., 2012. Derivation of a new model for prediction of wave overtopping at rubble-mound structures, ASCE J. Waterway, Port and Coastal Engineering, 138, 42-52.

Kazeminezhad, M.H., Etemad-Shahidi, A. and Yeganeh-Bakhtiary, A., 2010. An alternative approach for investigation of the wave-induced scour around pipelines, J. Hydroinformatics, 12, 51-65.

Pullen, T.A. \& Allsop, N.W.H. 2004. CLASH Workpackage 3.3: Samphire Hoe field measurements. Technical Report TR133, HR Wallingford.

Pullen, T., Allsop, N. W. H., Bruce, T., Kortenhaus, A., Schüttrumpf, H., andVander Meer, J.W., 2007. EurOtop:Wave overtopping of sea defences andrelated structures: Assessmentmanual,HRWallingford, Wallingford, U.K.

Quinlan, J. R. , 1992. Learning with continuous classes. Proceedings of AI'92 (Adams and Sterling Eds), World Scientific.

Sahay, R. R. and Dutta, S., 2009. Prediction of longitudinal dispersion coefficients in natural rivers using genetic algorithm. Hydrology Research, 40, 544-552.

Sakhare, S. and Deo, M. C., 2009. Derivation of wave spectrum using data driven methods. Marine Structures, 22, 594-609. 
Troch, P., Mollaert, J., Peelman, S., Victor, L.,van der Meer,J.,Gallach-Sánchez, D. and Kortenhaus, A., 2014. Experimental study of overtopping performance for the case of very steep sloped s and vertical walls with very small freeboards. Proceedings of 34th Conference on Coastal Engineering, P. Lynett ed.), Seoul, Korea, 1-8

Van Der Meer, J. W.,Verhaeghe, H. and Steendam, G. J., 2009. The new wave overtopping database for coastal structures. Coastal Engineering, 56, 108-120.

Van Der Meer, J. W. and Bruce, T., 2014. New physical insight and design formulas on wave overtopping at sloping and verticall structures. ASCE J. Waterway, Port and Coastal Engineering, 140, 04014025

Van Gent, M. R. A.,Van Den Boogaard, H. F. P.,Pozueta, B. and Medina, J. R., 2007. Neural network modelling of wave overtopping at coastal structures. Coastal Engineering, 54, 586-593.

Verhaeghe, H.,2005. Neural network prediction of wave overtopping at coastal structure. Doctorate Dissertation, Ghent University.

Verhaeghe, H., De Rouck, J. and Van Der Meer, J. , 2008. Combined classifier-quantifier model: A 2phases neural model for prediction of wave overtopping at coastal structures. Coastal Engineering, 55, 357-374.

Victor, L. and Troch, P. 2012. Wave overtoping at smooth impermeable steep slopes with low crest freeboards. ASCE J. Waterway, Port and Coastal Engineering, 138, 372-385.

Wang, Y. and Witten, I. H., 1997. Induction of model trees for predicting continuous lasses. Proceedings of the Poster Papers of the European Conference on Machine Learning, Prague. University of Economics, Faculty of Informatics and Statistics. 
Table 1. Ranges of dimensional parameters of the used dataset

\begin{tabular}{llll}
\hline Parameter & Training & Testing & Field data \\
\hline$R_{C}[\mathrm{~m}]$ & $0.010-6.410$ & $0.01-6.665$ & $5.590-8.490$ \\
\hline$H_{m 0}[\mathrm{~m}]$ & $0.029-2.002$ & $0.031-1.753$ & $1.33-2.57$ \\
\hline$d[\mathrm{~m}]$ & $0.05-2.265$ & $0.05-1.725$ & $0.19-2.80$ \\
\hline$h_{s}[\mathrm{~m}]$ & $0.050-4.515$ & $0.050-3.975$ & $2.44-5.05$ \\
\hline$L_{m-1,0}[\mathrm{~m}]$ & $0.983-58.235$ & $0.983-86.397$ & $43.362-66.168$ \\
\hline $\cot \alpha[-]$ & $0.0-0.10$ & $0.0-0.1$ & 0.0 \\
\hline $\tan \theta[-]$ & $0.10-0.001(\mathrm{flat})$ & $0.1-0.001$ & 0.0286 \\
\hline$q\left[\mathrm{~m}^{3} / \mathrm{s} / \mathrm{m}\right]$ & $1.021 \times 10-6-1.44 \times 10-2$ & $3.433 \times 10^{-6}-9.73 \times 10^{-3}$ & $5.0 \times 10^{-5}-3.30 \times 10^{-3}$ \\
\hline
\end{tabular}


Table 2. Ranges of used dimensionless parameters

\begin{tabular}{|c|c|c|c|}
\hline Parameter & Training & Testing & Field data \\
\hline$\frac{R_{C}}{H_{m 0}}$ & $0.082-6.245$ & $0.102-5.426$ & $2.240-6.165$ \\
\hline$\frac{d}{h_{s}}$ & $0.242-1.00$ & $0.242-1.00$ & $0.078-0.554$ \\
\hline$\frac{h_{s}^{2}}{H_{m 0} \cdot L_{m-1,0}}$ & $0.010-11.226$ & $0.010-11.078$ & $0.079-0.259$ \\
\hline$\frac{d}{H_{m 0}}$ & $0.852-15.556$ & $0.873-15.556$ & $0.143-1.242$ \\
\hline$\frac{H_{m 0}}{L_{m-1,0}}$ & $0.007-0.077$ & $0.007-0.081$ & $0.023-0.049$ \\
\hline$\frac{h_{s}}{L_{m,-1,0}}$ & $0.009-0.712$ & $0.009-0.712$ & $0.043-0.113$ \\
\hline$\frac{H_{m 0}}{h_{s}}$ & $0.033-1.00$ & $0.037-1.00$ & $0.437-0.694$ \\
\hline$\frac{d}{L_{m,-1,0}}$ & $0.009-0.712$ & $0.009-0.712$ & $0.003-0.061$ \\
\hline$d^{*}$ & $0.012-14.401$ & $0.012-14.401$ & $0.008-0.182$ \\
\hline $\tan \theta[-]$ & $0.1-0.001$ & $0.1-0.001$ & 0.029 \\
\hline$q^{*}=\frac{q}{\sqrt{g \cdot H_{m 0}^{3}}}$ & $3.43 \times 10^{-6}-4.56 \times 10^{-2}$ & $1.31 \times 10^{-5}-4.16 \times 10^{-2}$ & $5.73 \times 10^{-6}-2.56 \times 10^{-4}$ \\
\hline
\end{tabular}


Table 3. Accuracy metrics of different formulae, laboratory experiments.

\begin{tabular}{|c|c|c|c|c|c|c|c|c|c|c|}
\hline & \multicolumn{5}{|c|}{ All data } & \multicolumn{5}{|c|}{ Test data } \\
\hline & VB & Goda & EurOtop & MT1 & eq. 12 & VB & Goda & EurOtop & MT1 & eq. 12 \\
\hline BIAS & 0.19 & -0.003 & 0.048 & -0.040 & -0.042 & 0.13 & -0.057 & -0.045 & -0.120 & -0.127 \\
\hline$I_{a}$ & 0.84 & 0.86 & 0.70 & 0.82 & 0.90 & 0.83 & 0.85 & 0.76 & 0.79 & 0.88 \\
\hline RMSE & 0.58 & 0.57 & 0.54 & 0.56 & 0.46 & 0.51 & 0.49 & 0.50 & 0.50 & 0.41 \\
\hline DR Range & $-2.97 \_2.82$ & $-2.31 \_2.47$ & $-1.58 \_2.36$ & $-1.20 \_2.29$ & $-1.21 \_2.12$ & $-2.97 \_2.17$ & $-1.95 \_1.87$ & $-1.48 \_1.66$ & $-1.15 \_1.52$ & $-1.21 \_1.19$ \\
\hline$-1<D R<1$ & $91.3 \%$ & $91.3 \%$ & $91.4 \%$ & $92.3 \%$ & $94.6 \%$ & $94.0 \%$ & $94.0 \%$ & $93.1 \%$ & $94.4 \%$ & $96.6 \%$ \\
\hline
\end{tabular}


Table 4. Accuracy metrics of different formulae, field measurements.

\begin{tabular}{cccccc}
\hline & VB & Goda & EurOtop & MT1 & eq. 12 \\
\hline BIAS & 1.50 & 0.512 & 0.362 & 0.523 & 0.242 \\
\hline $\boldsymbol{I} \boldsymbol{a}$ & 0.36 & 0.55 & 0.64 & 0.56 & 0.66 \\
\hline $\boldsymbol{R} \boldsymbol{M S E}$ & 1.57 & 0.74 & 0.64 & 0.77 & 0.57 \\
\hline $\mathbf{1}$ <ange of $\boldsymbol{D} \boldsymbol{R}$ & $0.75 \_2.45$ & $-0.70 \_2.01$ & $-0.80 \_1.31$ & $-0.55 \_1.53$ & $-0.64 \_1.26$ \\
\hline
\end{tabular}


Table 5. Values of $N$ for different levels of acceptable risk (Yasa and Etemad-Shahidi, 2014).

\begin{tabular}{ll}
\hline Acceptable risk level (\%) & $\boldsymbol{N}$ \\
\hline 2 & 2.05 \\
\hline 5 & 1.65 \\
\hline 10 & 1.28 \\
\hline 33 & 0.44 \\
\hline 50 & 0.00 \\
\hline
\end{tabular}




\section{Figure captions}

Fig. 1. Comparison between the measured and predicted overtopping rates by the formulae of EurOtop (Pullen et al. ,2007), laboratory experiments. Circle: train data and Square: test data

Fig. 2. Comparison between the measured and predicted overtopping rates by the formula of Goda (2009), laboratory experiments. Circle: train data and Square: test data

Fig. 3. Decision chart and the formulae suggested by Van der Meer and Bruce (2014) for simple and composite vertical structures.

Fig. 4. Comparison between the measured and predicted overtopping rates by the formulae of Van der Meer and Bruce (2014), laboratory experiments. Circle: train data and Square: test data.

Fig. 5. Comparison between the measured and predicted overtopping rates by the eq. 11, laboratory experiments. Circle: train data and Square: test data.

Fig. 6. Comparison between the measured and predicted overtopping rates by eq. 12, laboratory experiments. Circle: train data and Square: test data.

Fig. 7. Histogram of $D R$, different formulae.

Fig. 8. The variation of $D R$ as a function of the relative crest freeboard (a) EurOtop (Pullen et al. 2007), (b) Goda (2009), (c) Van der Meer and Bruce (2014), and (d) eq. 12.

Fig. 9. Comparison between the measured overtopping rates and predicted ones using different formulae, field measurements of Samphire Hoe 


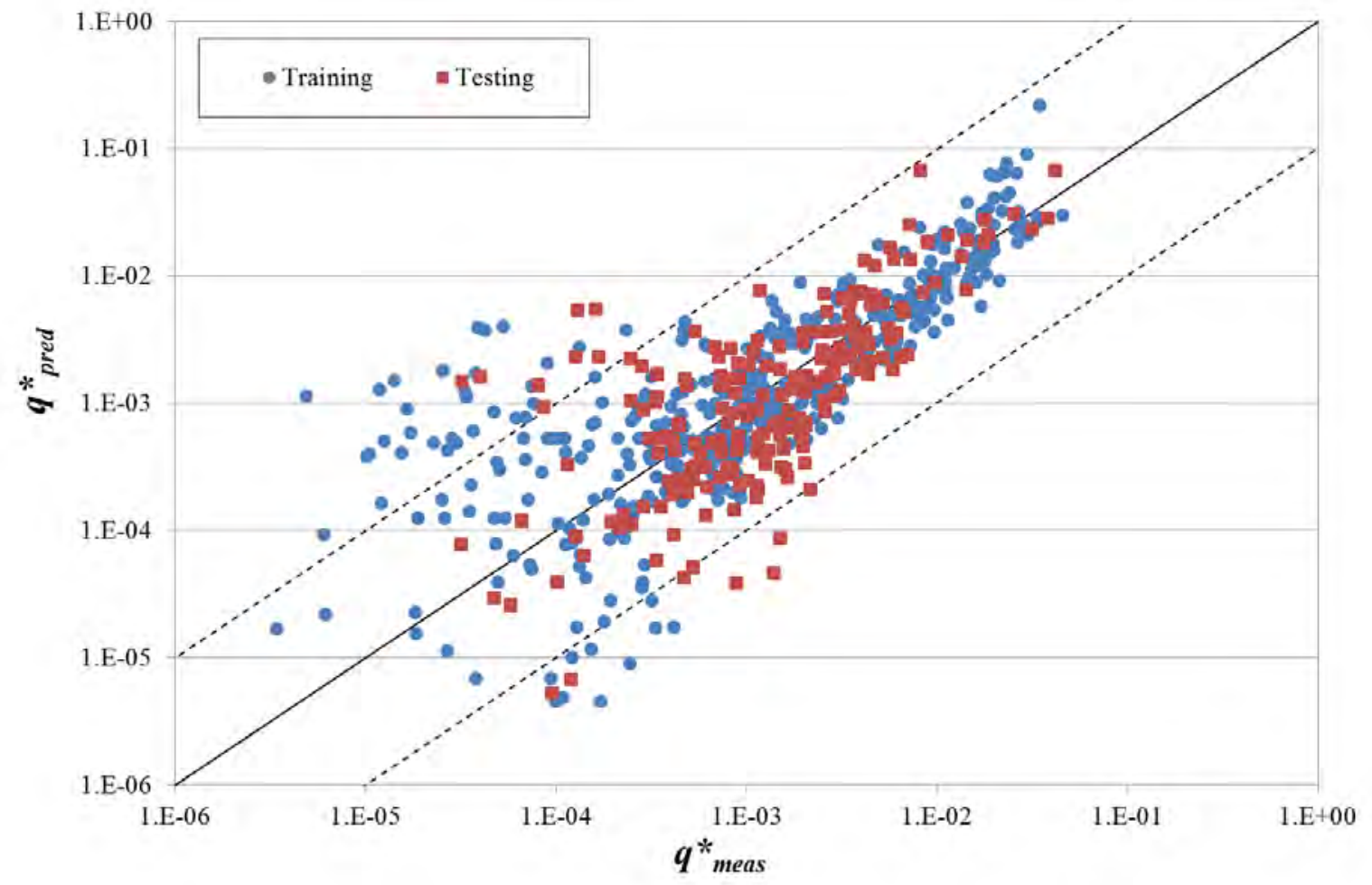

Fig. 1. Comparison between the measured and predicted overtopping rates by the formulae of EurOtop (Pullen et al. 2007), laboratory experiments. Circle: train data and Square: test data 


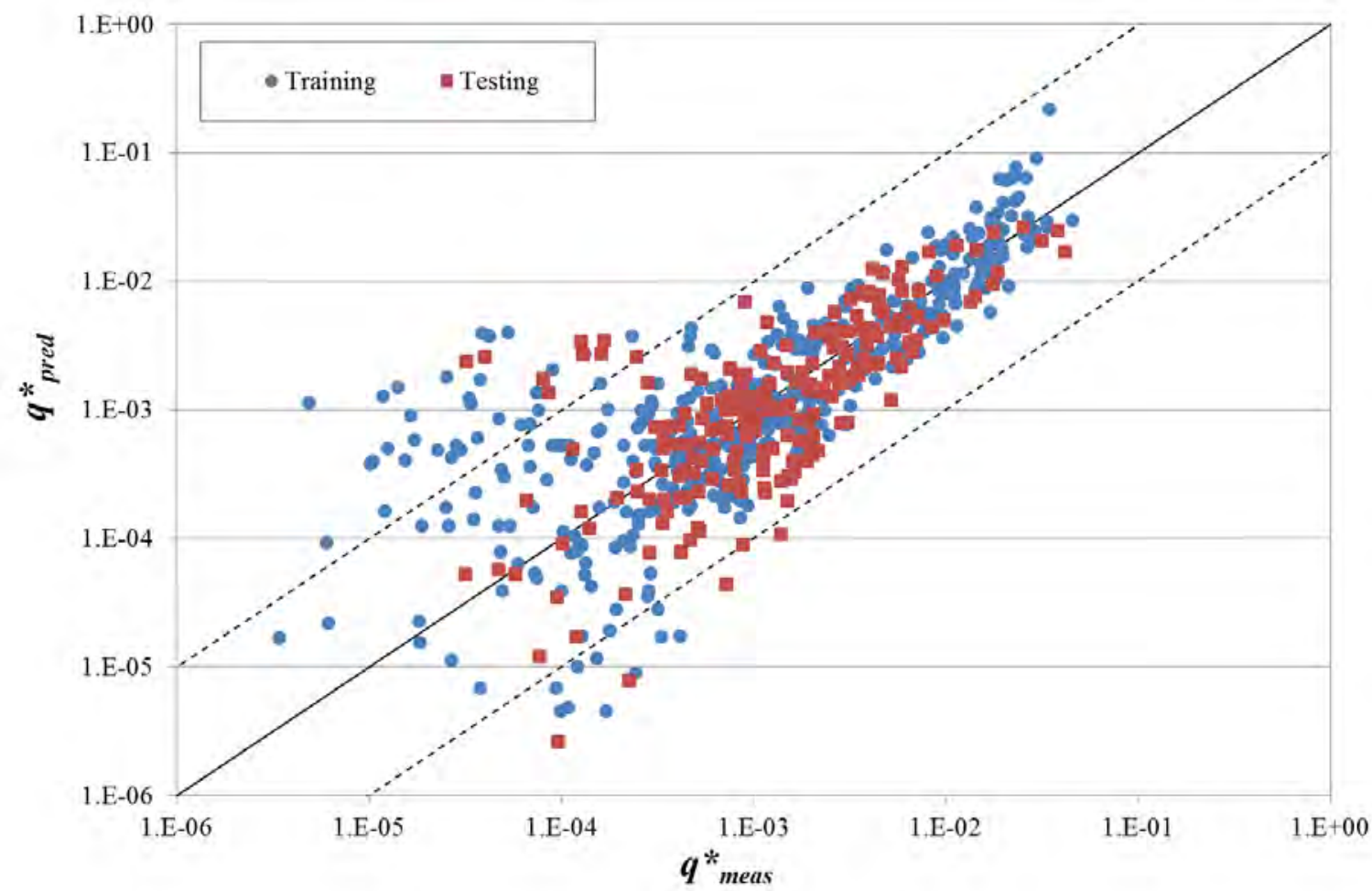

Fig. 2. Comparison between the measured and predicted overtopping rates by the formula of Goda (2009), laboratory experiments. Circle: train data and Square: test data 


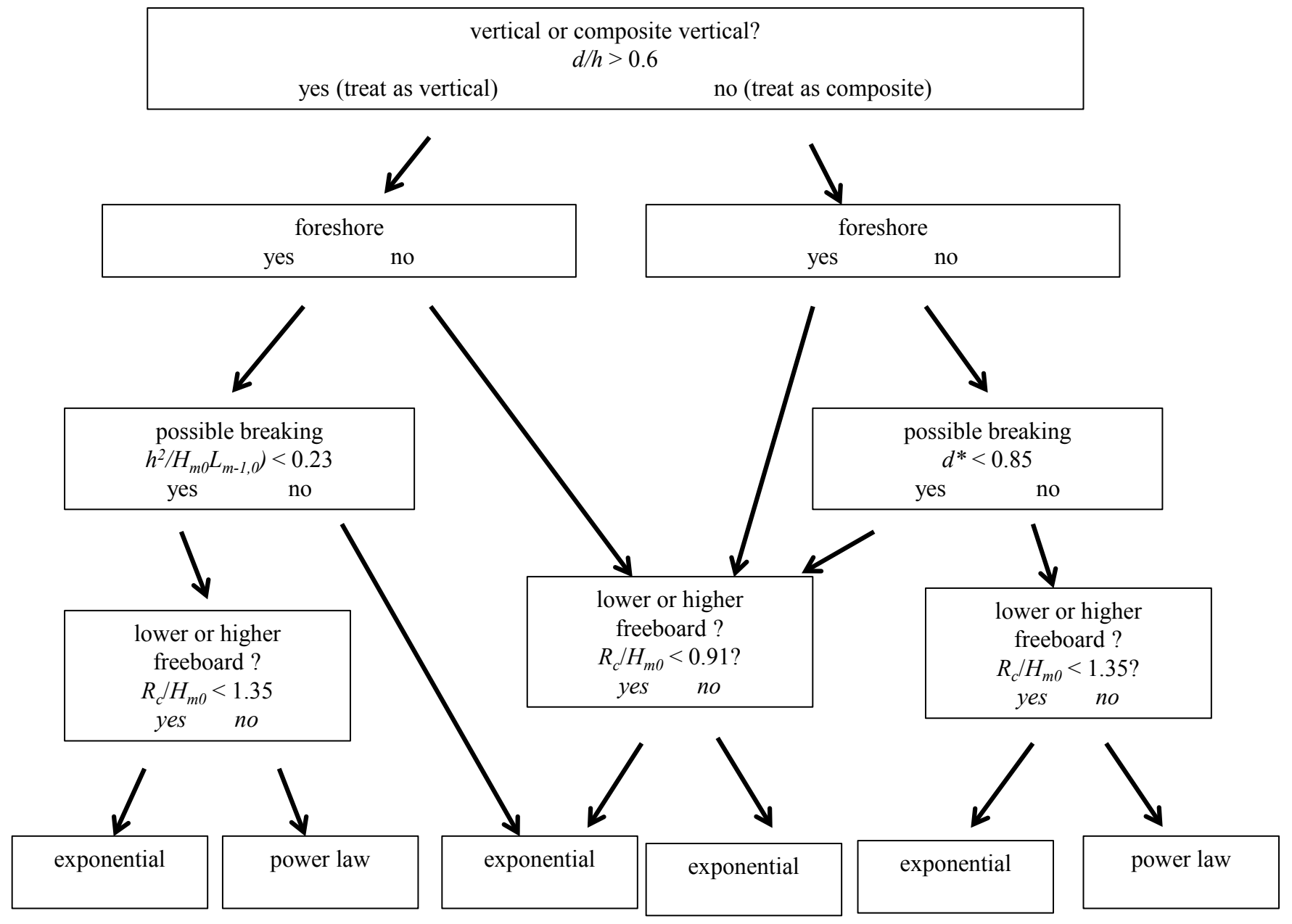

Fig. 3. Decision chart and the formulae suggested by Van der Meer and Bruce (2014) for simple and composite vertical structures. 


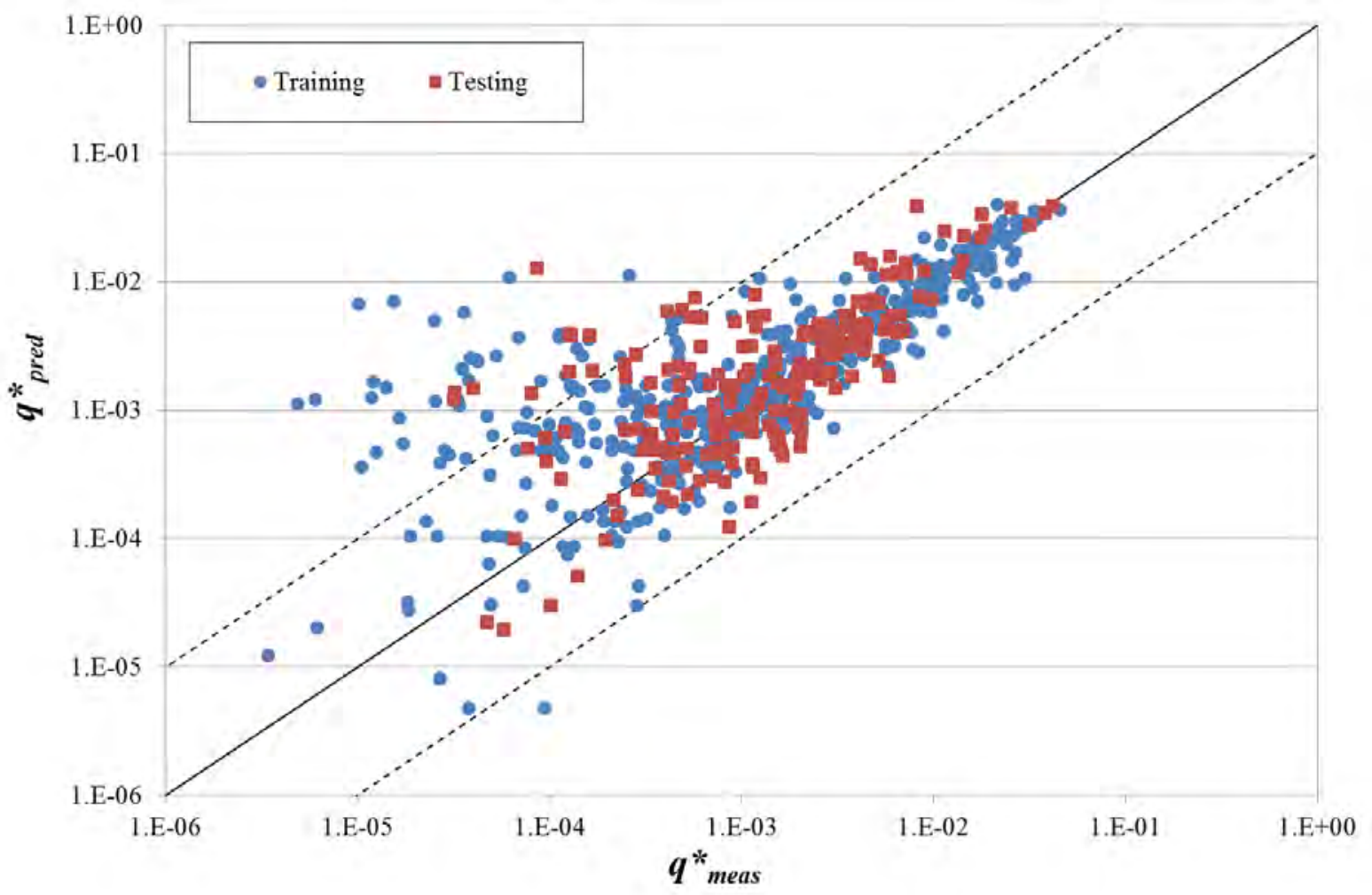

Fig. 4. Comparison between the measured and predicted overtopping rates by the formulae of Van der Meer and Bruce (2014), laboratory experiments. Circle: train data and Square: test data. 


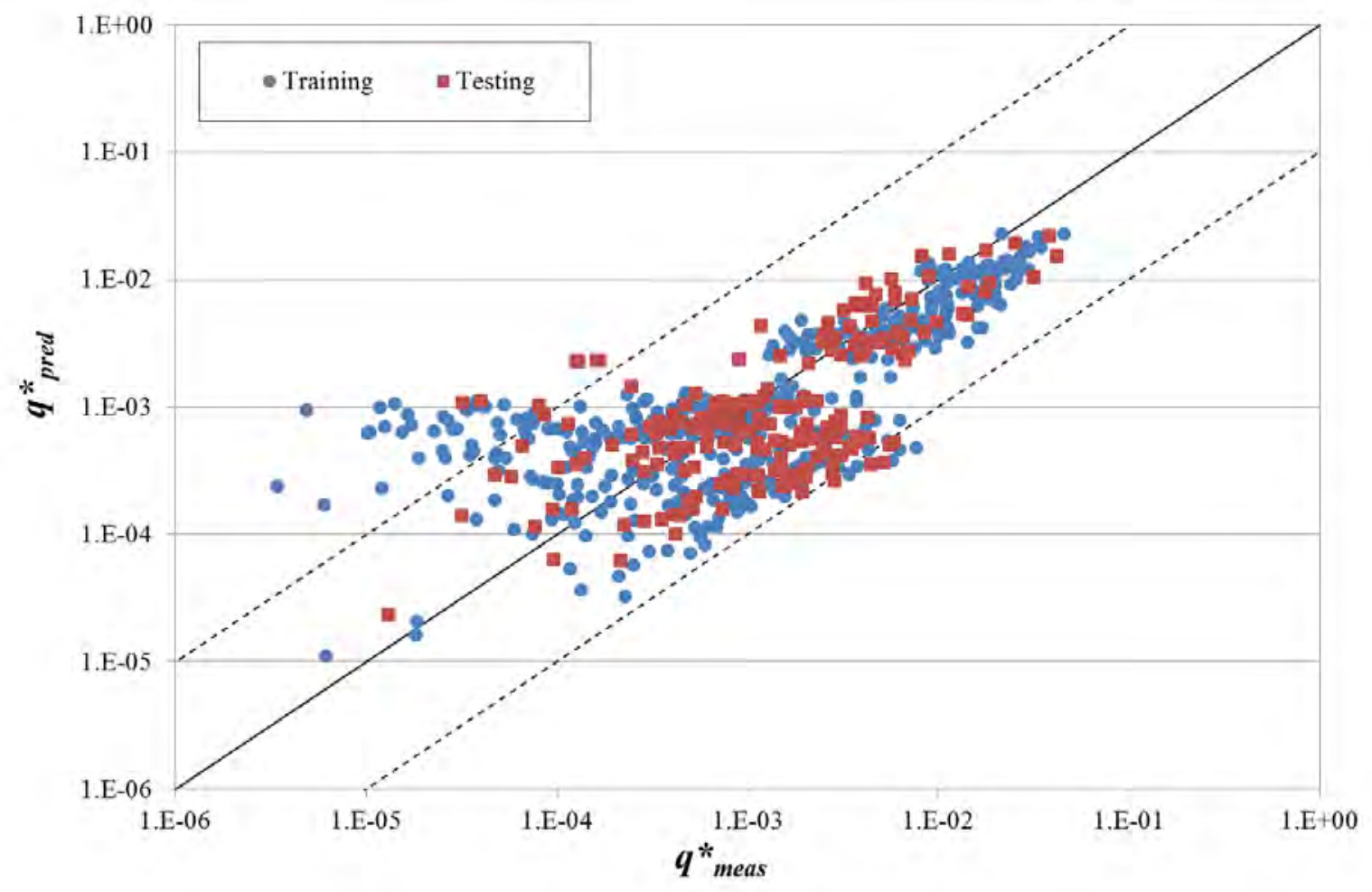

Fig. 5. Comparison between the measured and predicted overtopping rates by eq. 11, laboratory experiments. Circle: train data and Square: test data. 


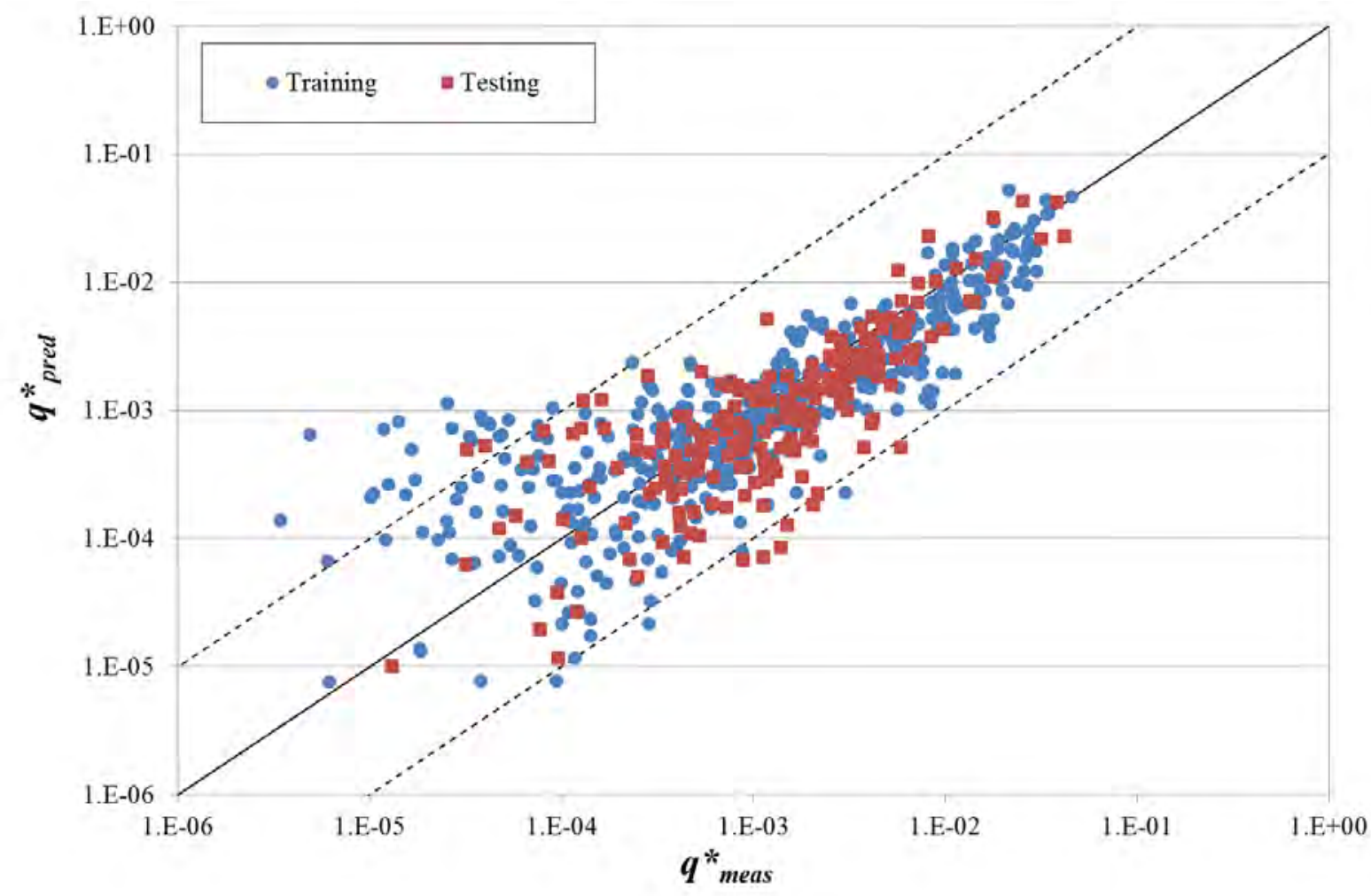

Fig. 6. Comparison between the measured and predicted overtopping rates by eq. 12, laboratory experiments. Circle: train data and Square: test data. 


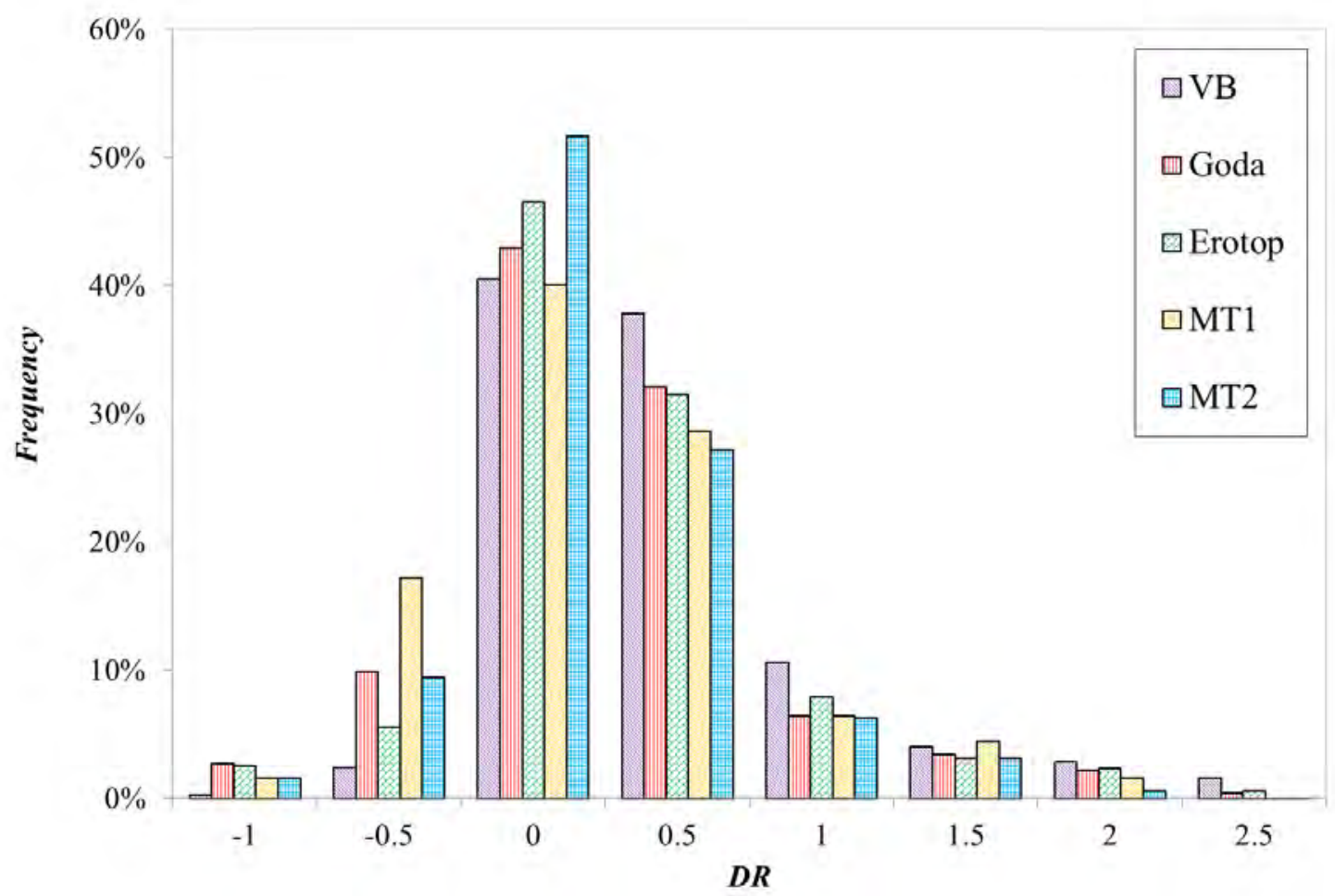

Fig. 7. Histogram of $D R$, different formulae. 


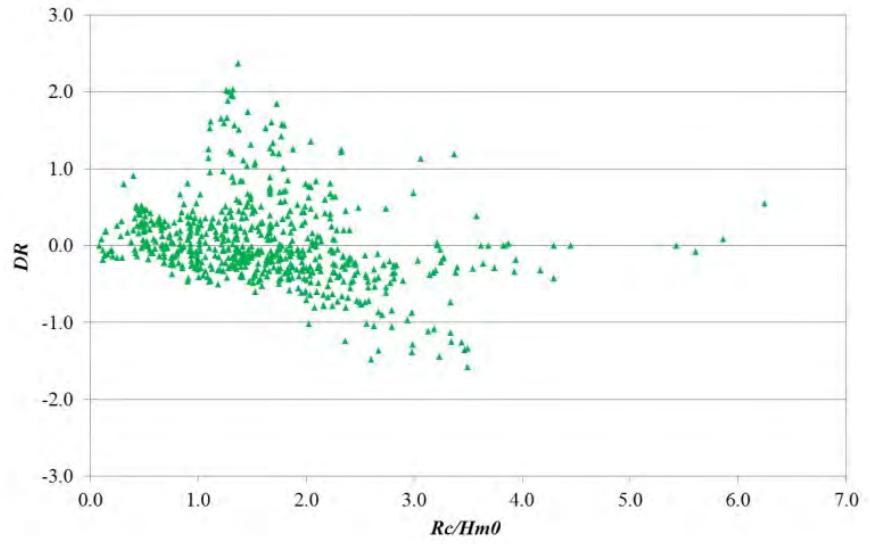

a)

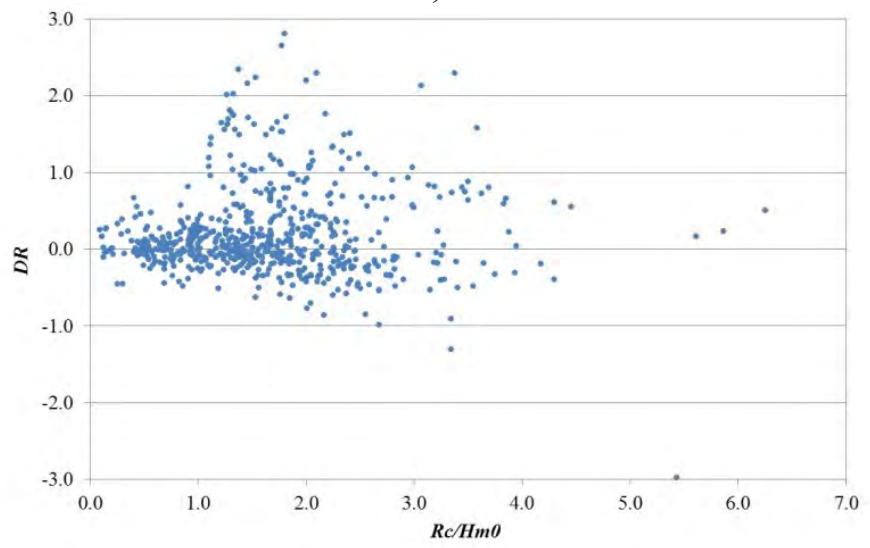

c)

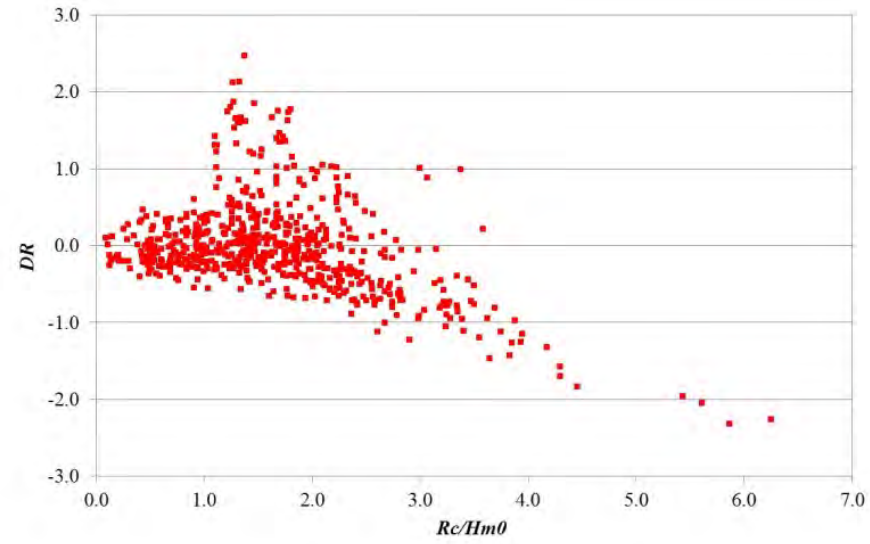

b)

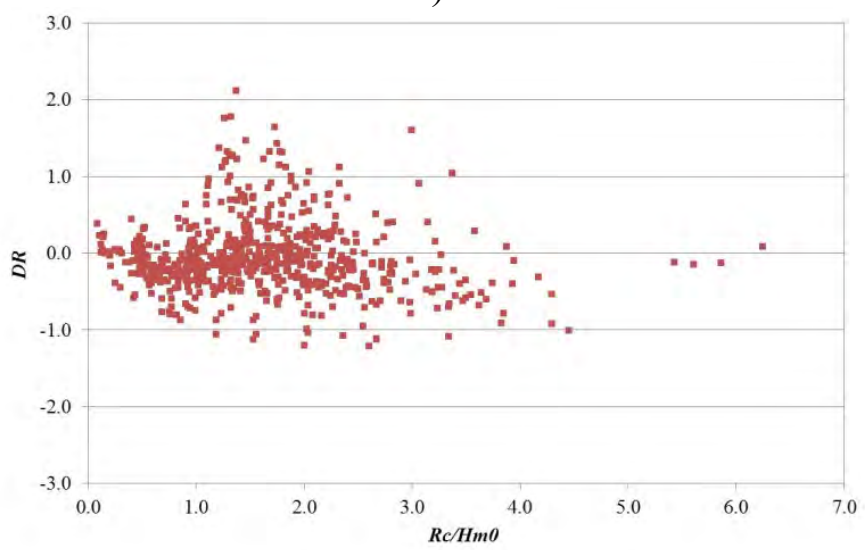

d)

Fig. 8. The variation of $D R$ as a function of the relative crest freeboard. (a) EurOtop (Pullen et al. 2007), (b) Goda (2009), (c) Van der Meer and Bruce (2014), and (d) eq. 12. 


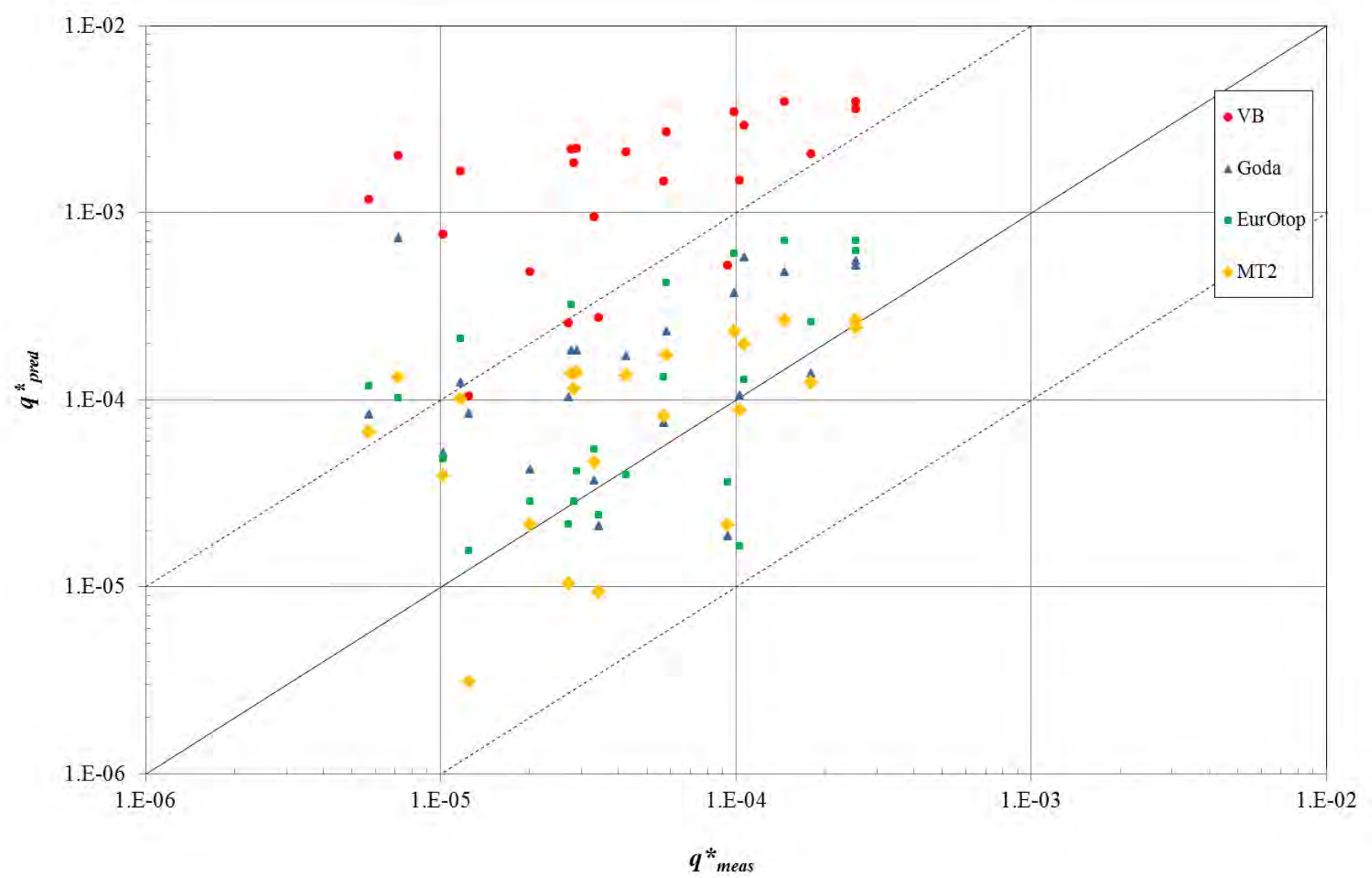

Fig. 9. Comparison between the measured overtopping rates and predicted ones using different formulae, field measurements of Samphire Hoe. 